\title{
A Feasibility Review for an Uneven Baseline Basis Minimal Ballast Ship
}

\author{
Hee Jin Kang® ${ }^{1}$, Kwang-Soo Kim $\oplus^{1,3}$, Jin Choi ${ }^{2}$, \\ Yeong-Yeon Lee® ${ }^{1}$, Haeseong Ahn $\oplus^{1}$ and Geun-Tae Yim® ${ }^{2}$ \\ ${ }^{1}$ Principal Researcher, Advanced Ship Research Division, Korea Research Institute of Ships and Ocean Engineering (KRISO), Daejeon, Korea \\ ${ }^{2}$ Senior Researcher, Autonomous Ship Research Department, Korea Research Institute of Ships and Ocean Engineering (KRISO), Daejeon, Korea \\ ${ }^{3}$ Senior Director, Advanced Ship Research Division, Korea Research Institute of Ships and Ocean Engineering (KRISO), Daejeon, Korea
}

KEY WORDS: Uneven baseline, Ballast water management (BWM), Minimal ballast water ship (MIBS), Non ballast water ship (NOBS), ballast water treatment system (BWTS), Ship resistance performance

ABSTRACT: Although there are many kinds of advanced ballast water management systems, pioneering studies for ballast-water free ship and minimal ballast water ship concepts are in progress. In this study, the existing alternatives of ballast water are reviewed and a new design concept is studied on the basis of the existing bulk carrier hull form. To develop a new design alternative which has minimal ballast for ballast water discharge free operation, the new concept should have technical feasibilities that are related to the role of the ballast water, berth access, loading constraints, etc. For this purpose, a simplified systems engineering basis design approach is adopted using a business model as the system analysis and control tool. To check the performance feasibility of the new concept, ship resistance performance is reviewed based on a model scale ship resistance performance analysis.

\section{Abbreviations}

\begin{tabular}{|c|c|c|c|}
\hline AUBAFLOW & automatic ballast flow & EARSM & explicit algebraic Reynolds stress model \\
\hline BW & ballast water & EHP & effective horsepower \\
\hline BWE & ballast water exchange & FOC & fuel oil consumption \\
\hline BWM & ballast water management & IGES & initial graphics exchange specification \\
\hline BWTS & ballast water treatment system & ISO/IEC & $\begin{array}{l}\text { international organization for standardization/ } \\
\text { international electro-technical commission }\end{array}$ \\
\hline CFD & computational fluid dynamics & KPPs & key performance parameters \\
\hline CSR-H & harmonized common structural rules & $\mathrm{KB}$ & vertical distance between the keel and the center of buoyancy \\
\hline$C_{f}$ & friction resistance coefficient & MIBS & minimal ballast water ship \\
\hline$C_{p}$ & prismatic coefficient & $\mathrm{MOE}$ & measure of effectiveness \\
\hline$C_{t m}$ & total resistance coefficient of model-scale ship & MOP & measure of performance \\
\hline$C_{f m}$ & $C_{f}$ of model-scale ship & NOBS & non-ballast water ship \\
\hline$C_{f s}$ & $C_{f}$ of full-scale ship & RANS & Reynolds-averaged Navier-Stokes \\
\hline$C_{r}$ & residuary resistance coefficient & TA & trim aft \\
\hline$C_{t s}$ & total resistance coefficient of full-scale ship & $\mathrm{TF}$ & trim forward \\
\hline D-1 & regulation about ballast water exchange & $\mathrm{Tm}$ & mean draft at a midships \\
\hline D-2 & regulation about ballast water treatment & TPMs & technical Performance measures \\
\hline DHP & delivery horsepower & WAVIS & wave and viscous flow (proprietary brands) \\
\hline DISV & displacement volume & VLCC & very large crude oil carrier \\
\hline DWT & deadweight tonnage & ULCC & ultra large crude oil carrier \\
\hline
\end{tabular}

Received 16 December 2019, revised 13 February 2020, accepted 14 February 2020

Corresponding author Hee Jin Kang: +82-42-866-3417, hjkang@kriso.re.kr

It is noted that this paper is revised edition based on proceedings of IMAM 2017 in Lisbon.

(c) 2020, The Korean Society of Ocean Engineers

This is an open access article distributed under the terms of the creative commons attribution non-commercial license (http://creativecommons.org/licenses/by-nc/4.0) which permits unrestricted non-commercial use, distribution, and reproduction in any medium, provided the original work is properly cited. 


\section{Introduction}

Because the measures from the Ballast water management (BWM) convention are being enacted in order to reduce the environmental damage caused by the global movement of marine life in the ballast water of ships (Albert et al., 2013), the negative effect of treated ballast water on the marine environment is another urgent issue (Werschkun et al., 2014). Notably, research on non/minimal ballast water vessels is actively underway in response to the D-1 or D-2 discharge standards of the convention. When considering the role of ballast water, as shown in Table 1, the ballast water contributes to the ship's stability via proper maintenance of the draft and the center of gravity of a ship during voyage. Another aim of the ballast water is to maintain the appropriate immersion depth of the propeller for propulsion efficiency.

Table 1 Roles of the ballast water in a ship (Isbester, 2010)

Maintain the stability of the ship

Trim and heel control

Secure immersion depth of the propeller

Reduction of slamming

Reduction of the bending moment of the ship

Relieve the shear force of the ship
Ballast water is also used to adjust the trim and heel of a ship. The bending moment and shear force can also be adjusted by the ballast water.

Depending on the ship types and routes, generally, $30 \%$ to $40 \%$ of the deadweight tonnage (DWT) is used as ballast water (Kerr, 1994). Many pioneering studies have been conducted to meet the D-1 or D-2 discharge standards of the BWM convention without needing to discharge the environmentally harmful ballast water. Table 2 shows alternatives for the BWM methods (GEF, U. and IMO, G.P., 2011).

Among the various alternatives, in the case of 'no or minimal discharge' alternatives, the minimal ballast water ship (MIBS) and non-ballast water ship (NOBS) (Shingo, 2014) of a 'storm ballast' are considered to be practically applicable alternatives. Though there are some constraints for berthing and loading, in 2018, a NOBS concept basis ballast water-free '7,500 cubic meter liquefied natural gas (LNG) bunkering vessel' was launched for commercial purposes (https:// pulsenews.co.kr). For the 'continuous flow' type alternatives, 'The Variable Buoyancy Ship Concept' of 'longitudinal trunks' is remarkable. For the trim and heel control, the concept has been shown to adequately control the trim and draft (Parsons and Kotinis, 2011a; Parsons and Kotinis, 2011b). In this study, a new design concept for 'no or minimal discharge' alternatives is studied while considering the ship's size and operational conditions.

Table 2 Alternatives for the BWM methods [derived and edited from GEF, U. and IMO, G. P. 2011]

\begin{tabular}{|c|c|c|c|c|}
\hline \multirow{2}{*}{\multicolumn{5}{|c|}{$\frac{\text { Alternative methods }}{\text { No ballast water }}$}} \\
\hline & & & & \\
\hline · Zero ballast & $\begin{array}{l}\text { (a) Novel hull design } \\
\text { (b) Use of 'solid ballast } \\
\text { TEUs' }\end{array}$ & $\begin{array}{l}\text { Avoids all cost associated } \\
\text { BWM }\end{array}$ & $\begin{array}{l}\text { Higher hull build/ operating } \\
\text { cost }\end{array}$ & $\begin{array}{l}\text { (a) Ro-ro pax, car, } \\
\text { container, high volume } \\
\text { cargo ships } \\
\text { (b) Existing box ships }\end{array}$ \\
\hline
\end{tabular}

No or minimal discharge

- Storm ballast

(must meet D-2)

Wide beam V-hull design

Avoids cost of large BWTS

- Internal ballast

(must meet D-2)

Fresh water shifted from tank to tank

Portable water (must meet D-2)
Only drinking water is added to clean tank/s
Higher building cost, berth New dry bulk carriers access or loading constraints due to wider beam

Reduces cargo capacity, air-draught, tank survey/ inspection

Cost of potable water production/purchase livestock carriers
Avoids all cost of BWTS

Avoids costs and loss of space for BWTS
Existing and new container ships, ro-ro pax, liners,

Super yachts, cruise liners, some livestock carriers, pax and military vessels

Continuous flow

- Longitudinal trunks (meets D-1 and may equivalent to D-2)

- Ship buoyancy control (meets D-1 and may equivalent to D-2)

- AUBAFLOW

(exceeds D-1)

- Loop ballast exchange (above D-1 and may approach D-2)

- Dyna ballast (exceeds D-1)
Replaces ballast tanks with Avoids costs of large buoyancy trunks

Multiple valves convert each BW tank into a free flooding buoyancy compartment BWTS and propeller efficiency gain/s Avoids costs of BWE pumping and very large BWTS

Enhanced bluewater BWE Avoids costs of BWTS pumping
Higher build costs, risk of biota/sediment accumulation prevent

Costs of multiple valves Existing and new cargo and control systems, valve ships servicing, coating and cleaning, slight increase to Existing and new VLCCs + hull drag
New Seaway-size and other large bulk carriers

ULCCs
Any sediment/biota accumulating in a low-flow new cargo ships 


\section{Feasibility Study}

To design a new minimal ballast vessel, a ship must be designed that has the functions of ballast water without or with the minimum use of ballast. The perspectives of performance, ship stability, resistance, trim and heel controllability, berth access and loading constraints should be considered. Technical complexity and cost related matters are also considered to ensure technical and economic feasibility.

To compensate for the existing BWM alternatives' penalties, an appropriate approach and design process are required. In a systems engineering process, it is essential to identify, validate, and verify the various constraints of shipbuilding and operation in the design phase for the development of minimal ballast water vessel. Generally, the systems engineering basis design process involves a "system analysis and control tool", which allows for the effective management of various design entities from various viewpoints, including technical and economic feasibility (Leonard, 1999; Kang et al., 2016). In this study, the business model was used as a system analysis and control tool, which was suggested by Kang et al. (2016). The business model consists of six elements: the design of a new concept for a minimal ballast vessel (Task); the required value of the enhanced berth access and loading capability compared to the existing 'MIBS' (Value); the expected revenue of the designed concept, such as a decrease in the ecosystem disturbance (meeting D-2) and the reasonable hull build cost (Revenue); the available and considered infrastructure, such as port facilities, ships in operation, rules and regulations, ship yards (Infra); the channels to enable the design concepts, such as technical and economic feasibilities (Channel); and the stakeholders of the task, including ship owners, ship builders, port authorities, classification societies, and fishing industries (Stakeholder). The factors considered in this study are shown in Table 3.

By adopting a business model for the systems analysis and a control tool for the design process, the ISO/IEC 15288-based 'Vee' design process was adopted and modified, as shown in Fig. 1. In the early phase of the design process, the measure of effectiveness (MOE), key performance parameters (KPPs), measure of performance (MOP) and technical performance measures (TPMs) should be identified in order to validate and verify the feasibility of the design results in the early phase of the design process. During the design process, all the design aspects should be analyzed and determined within the boundaries of

Table 3 Business model for a new non / minimal ballast ship design

\begin{tabular}{ll}
\hline Task & Minimal ballast operation of a ship \\
Value & Enhanced berth access and loading capability compare to existing 'MIBS' \\
Revenue & Decrease in ecosystem disturbance (meeting D-2), a reasonable hull build cost \\
Infra & Port facilities, ships in operation, rules and regulations, shipyards \\
Channel & Technical and economic feasibility \\
Stakeholder & Ship owners, ship builders, port authorities, classification societies, fishing industries \\
\hline
\end{tabular}

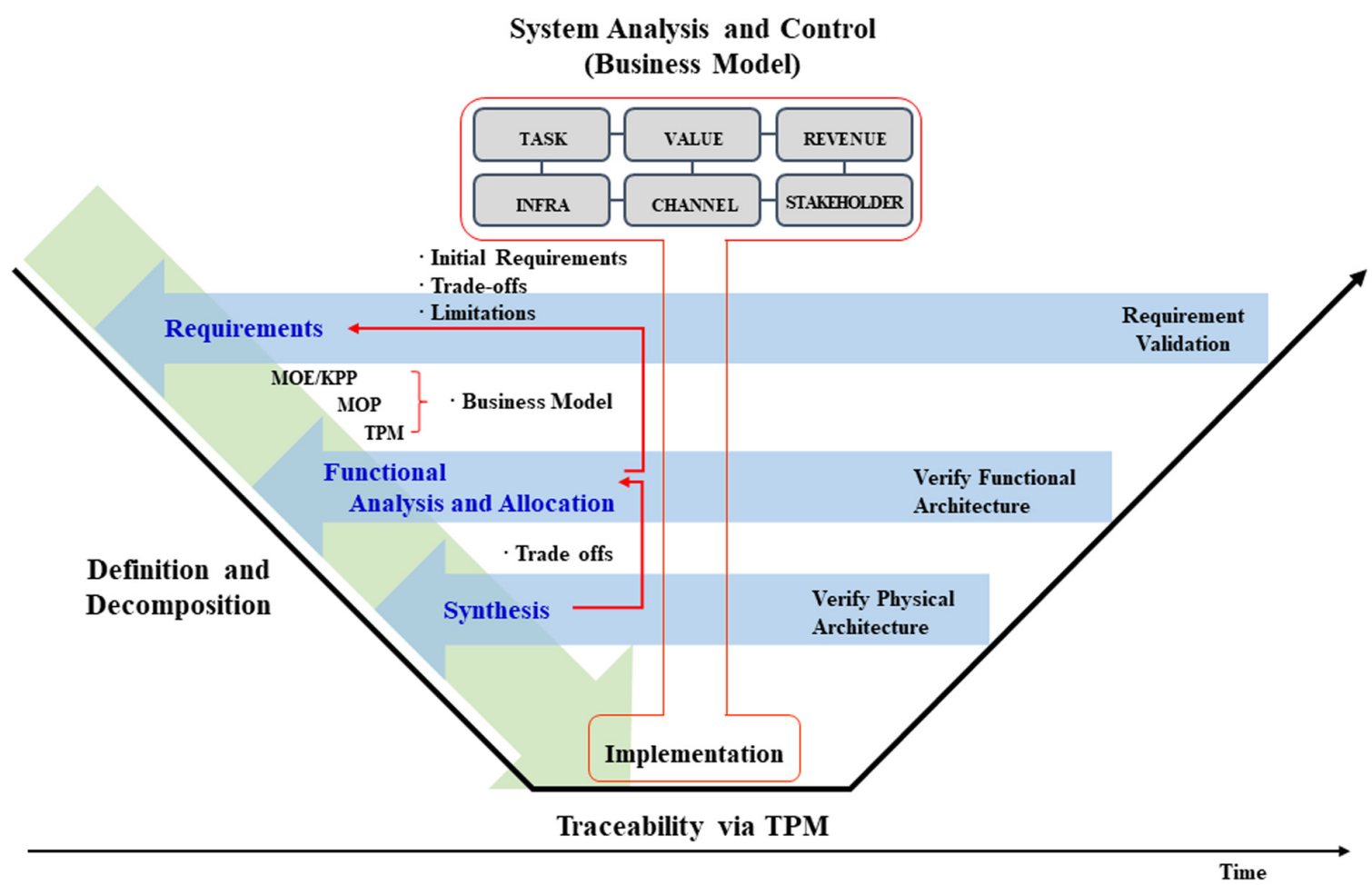

Fig. 1 Design process for a new minimal ballast ship design [derived and edited from (Kang et al., 2016)] 
the defined business model.

\subsection{Requirement analysis}

To achieve this goal, eight requirements were derived, as shown in Table 4. R1 to R7 are the general requirements for a non/minimal ballast water ship. The new design should meet the requirements at the same level as the previous alternatives. $\mathrm{R} 8$ is the requirements to overcome the existing difficulties of a 'storm ballast' of the 'no or minimal discharge' alternatives.

$\mathrm{R} 1$ is a requirement related to the stability of a ship. When changing the existing hull form, such as the MIBS, it is difficult to achieve the same stability as that of the existing ship. In such cases, the placement of the keel or stabilizer should be reviewed in terms of the dynamic behavior, propulsion power of the ship, and cost. $\mathrm{R} 2$ is a requirement for the trim and heel control, considering the weight distribution of cargo. R3 stipulates the immersion depth required for securing the self-propulsion capability of a ship. R4 is a requirement related to the operation cost of the ship. R5 states the condition for bow slamming reduction, which should be considered together with R3 to ensure the proper immersion depth of the bow. R6 and R7 are requirements for managing the load applied to the ship according to the cargo weight distribution and the arrangement of the ballast of the ship. R8 requires that the designed concept should be able to utilize the existing port facilities. From the results of the analysis of the requirements, the TPMs are generated and shown in Table 5. The TPM is generated from each essential requirement for a minimal ballast ship, and the MOP is measured after all TPMs are satisfied. Then, the MOE / KPP can be evaluated as a considerable design result.

\subsection{Functional analysis and allocation}

Each requirement should be functionalized for the new minimal ballast ship design. To functionalize the requirements R1-R5 in Table 4, technologies pertaining to fluid performance are required. R6 and $\mathrm{R} 7$ are the requirements related to the structural strength, and R8 requires the ship be able to be adapted to existing harbor facilities. The functions to accommodate each requirement are listed in Table 6, including all the identified requirements.

\subsection{Synthesis}

In the synthesis process, the design alternatives shall be generated to implement the functions in Table 6 within the boundaries of the business model. To implement F1 and F4, any requirements for new rules and regulations should be minimized. In addition, the existing rules and regulations for ship stability and structural strength must be satisfied. For F2, a minimum level of the propeller immersion depth and bow draft must be achieved. For F3, any type of external attachment should be avoided to ensure the appropriate ship resistance performance. For F4 and F5, changes in the draft, beam, and bilge radius of the existing ship should be limited to ensure the berth access and usability of cargo loading facilities. The adjustment of the baselines of the bow and stern of a ship can be used to meet the functional requirements. However, when considering the required couplings and machinery systems among the bow, stern, and cargo hold parts of the ship for adjusting the baseline, the design concept shown in Fig. 2 does not meet the 'revenue' of the business model.

Since it is practically impossible for an adjustable hull form to meet the requirements of Table 4 and the business model of Table 3 , to build

Table 4 Redefined requirements for the new non/minimal ballast ship design

\begin{tabular}{llll} 
R1 & Maintain the stability of the ship & R5 & Reduction of slamming \\
R2 & Trim and heel control & R6 & Reduction of the bending moment of the ship \\
R3 & Secure immersion depth of the propeller & R7 & Relief of the sheer force of the ship \\
R4 & Ensure the ship resistance performance & R8 & Harbor operability (berth access / loading constraints) \\
\hline
\end{tabular}

Table 5 Criteria, thresholds and indicators for TPMs

\begin{tabular}{clll}
\hline & & \multicolumn{1}{c}{ Criterion } & \multicolumn{1}{c}{ Threshold } \\
\hline & TPM1 & Ship stability & Meet the rules and regulations \\
TPM & TPM2 & Trim and heel control & Same as original hull form \\
& TPM3 & Resistance performance & Minimum increase in EHP \\
& TPM4 & Structural strength & Meet the related CSR-H \\
& TPM5 & Harbor operability & Berth access/loading constraints \\
\hline
\end{tabular}

** CSR-H: Harmonized Common Structural Rules

Table 6 Function list for new non/minimal ballast ship design

\begin{tabular}{llll}
\hline F1 & Function to maintain ship stability & TPM1 & R1 \\
F2 & Trim and heel control function & TPM2 & R2, R3, R5 \\
F3 & Function to maintain resistance performance & TPM3 & R4 \\
F4 & Function to sustain the structural strength of the ship & TPM4 & R6, R7 \\
F5 & Function for berth access and usability for loading facilities & TPM5 & R8 \\
\hline
\end{tabular}




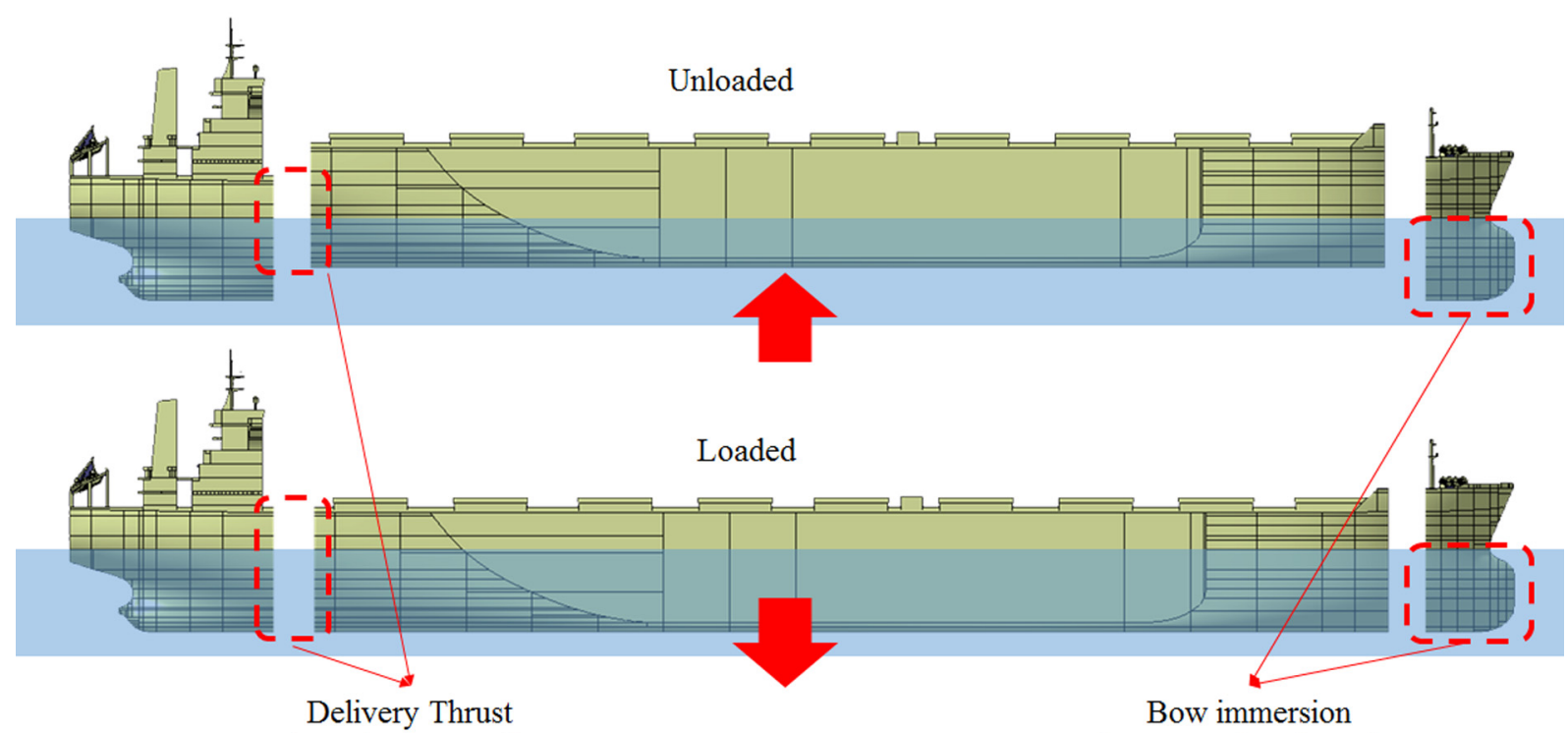

Through the coupling

for preventing slamming

Fig. 2 An initial concept of the adjustable bow, stern and cargo hold baselines for non/minimal ballast operation

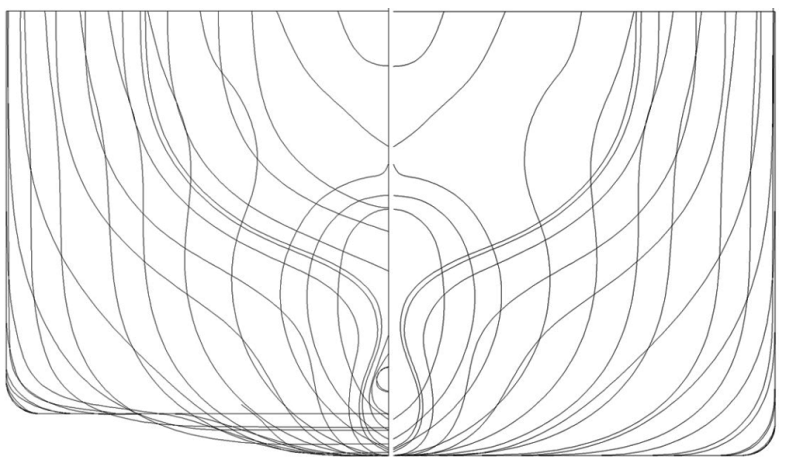

Fig. 3 Body plan, modified (left side) and original (right side) hull form

a reasonable design alternative for the functions in Table 6, a fixed type uneven baseline hull form (modified) has been generated on the basis of an existing $176 \mathrm{~K}$ bulk carrier hull form (original). Fig. 3 shows the body plan of an uneven baseline minimal ballast bulk carrier.

From the Fig. 3, the suggested 'modified' hull form has uneven baselines of the bow, stern, and cargo holds. These differences should be addressed because an uneven baseline can affect the ship's resistance performance. In addition, an uneven baseline interferes with the fluid flow and affects the seakeeping ability for F1. Furthermore, measures should be taken to secure the longitudinal strength under repetitive hogging and sagging conditions. To reduce the adverse effects of the shear force and bending moment on the structural strength of the hull, the heel trim must be carefully weighed and controlled during the cargo loading process. For F1 and F4, a center-line bottom keel-based structural reinforcement can be used. While a fin-stabilizer for F1 has no effect on the normal concept of the static stability of a ship, it has a positive effect on the dynamic stability. Since the fin is usually not considered for a large ship, the cost effectiveness and possible capacity of the fin should be considered before implementation. To obtain the proper immersion depth of the propeller of the designed ship, a reduction of the propeller diameter can be considered by changing from a single-screw to twin-screw propulsion with an uneven baseline. In addition, for non-ballast exchange operation in certain loading conditions, a permanent ballast system will be required for F2 and F5. In this case, the operation of the permanent ballast should take the water depth and loading condition control ability of the port into account. The design should also consider the amount of required permanent ballasts for securing the appropriate immersion depth and a safe return voyage with empty cargo holds. By increasing the baseline of the cargo holds,

Table 7 Initial dimensions of the designed ship

\begin{tabular}{lll}
\hline & Original & Modified \\
\hline Length (p.p.) & $282.00 \mathrm{~m}$ & $282.00 \mathrm{~m}$ \\
Breadth (mld) & $45.00 \mathrm{~m}$ & $45.00 \mathrm{~m}$ \\
Draught laden (Draught ballast TA) & $17.70 \mathrm{~m}(7.70 \mathrm{~m})$ & $17.70 \mathrm{~m}(6.70 \mathrm{~m})$ \\
Trim & $-0.175 \mathrm{~m}$ & $-0.176 \mathrm{~m}$ \\
Baseline of cargo holds & - & $2.45 \mathrm{~m} \mathrm{elevated}$ \\
GM (metacentric height) & $4.88 \mathrm{~m}$ & $6.84 \mathrm{~m}$ \\
Deadweight & $168,310 \mathrm{t}$ & $127,935 \mathrm{t}$ \\
\hline
\end{tabular}


Table 8 List of developments for a new non/minimal ballast ship design

\begin{tabular}{lcc}
\hline S1 & Uneven baseline of cargo holds & F2 and F5 \\
S2 & Permanent ballast system only for loading and unloading & F4 \\
S3 & Bottom keel system & F1 and F3 \\
\hline
\end{tabular}

Table 9 Geometry and principal particulars of the model ship for CFD

\begin{tabular}{|c|c|c|c|c|}
\hline Original & & & & \\
\hline \multicolumn{5}{|l|}{ Modified } \\
\hline Condition & Original & Modified & Original & Modified \\
\hline $\operatorname{Tm}(\mathrm{m})$ & 17.7 & 17.7 & 0.5429 & 0.5429 \\
\hline$S\left(\mathrm{~m}^{2}\right)$ & 19,981 & 19,113 & 18.8015 & 17.9843 \\
\hline Design speed & \multicolumn{2}{|c|}{$15 \mathrm{kt}(7.717 \mathrm{~m} / \mathrm{s})$} & \multicolumn{2}{|c|}{$1.3515(\mathrm{~m} / \mathrm{s})$} \\
\hline
\end{tabular}

※ Tm (Draft of the ship), $S$ (Area of wetted surface)

the wetted surface area is decreased slightly, which can contribute to the ship's resistance performance. However, since the uneven baseline may have a negative effect on the ship resistance performance, the feasibility of design alternatives for F3 should be carefully examined. For F4, in the hull form modification process the applicability of the hull form to the existing rules and regulations is considered.

The provisional specifications of the designed ship are described in Table 7. From the hull form modification of the existing 176K bulk carrier, the wetted surface is reduced by approximately $4.4 \%$ compared to those of the original hull form under full loaded conditions. Under ballasting conditions, the required fixed ballast was estimated at approximately $42,000 \mathrm{t}$ for a $7.5 \mathrm{~m} \mathrm{TA}$.

The synthesis results of reviewing the technical alternatives for the required functions are summarized in Table 8 . The conceptually designed ship was reconfigured from the existing 176K bulk carrier. The tanks for the ballast are minimized and the auxiliaries and superstructure have been relocated for the initial trim and heel conditions. For S1, the uneven baseline of the cargo holds, consideration should be given to the influence of these differences on the ship's resistance performance, structural safety, and workability at shipyards. For S2, the amount of permanent ballast should be minimized to consider the controllability of the loading weight distribution. Finally, for S3 the bottom keel should be properly configured to prevent it from detaching from the baseline of the bow and stern.

\section{Ship Resistance Performance basis Feasibility Evaluation}

The ship resistance performance affects the operating cost, and especially the fuel oil consumption. For this reason, the ship resistance performance should be determined in the early design phase. Although the model ship basin test is recommended, for a fast and effective evaluation in this study, a computational fluid dynamics (CFD)-based evaluation was adopted with the model ship basin test results and the sea trial data of an existing $176 \mathrm{~K}$ bulk carrier. Thus, when the evaluation results have economic feasibility, the model ship-based test will be adopted in the next study. For the model scale CFD simulation, (a)

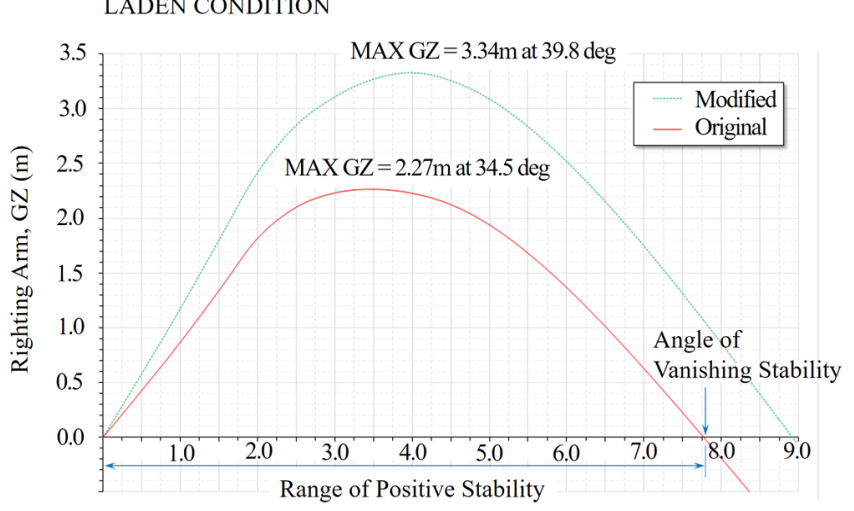

(b)

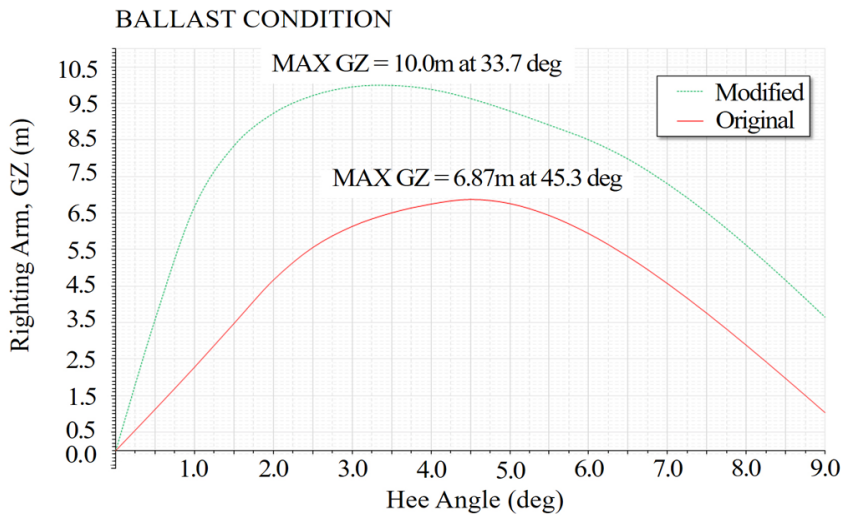

Fig. 4 GZ curves of the original and the modified hull form, (a) Laden condition (b) Ballast condition 
a hull model is generated, as described in Table 9.

Regarding the ship's stability performance, the designed uneven baseline hull form has a larger righting arm compared to the original hull form, as shown in Fig. 4.

For the model scale CFD simulations, the Reynolds-averaged Navier-Stokes (RANS) equation-based Wave and viscous flow (WAVIS) software which KRISO (Korea Research Institute of Ships and Ocean Engineering) developed and widely used in Korean ship yards was used. As shown in Table 10, understanding the simulation of the flow around the ship helps in generating an accurate grid arrangement. The grid includes the free surface area with a total of $3.6 \mathrm{M}$ grid points for the half domain, which is equivalent to the medium size grid in a previous study (Kim et al., 2011). Starting from the initial graphics exchange specification (IGES) description of the 'original' and 'modified' hull forms, the commercial program GRIDGEN (Pointwise, Inc.) was used to generate the H-O type multiblock structured grid systems. In the CFD simulation in this study, the free surface was captured using the level-set method, while for the turbulence closure, the Explicit algebraic reynolds stress model (EARSM) was used with Launder and Spalding's wall function. The details of the numerical methods used can be found in Kim et al. (2011), Kim et al. (2014).

From the numerical resistance test, as shown in Table 11, the effective horsepower (EHP) was predicted to increase from 1.5 to $2.0 \%$, depending on the speed of the bulk carrier, compared to the existing $176 \mathrm{~K}$ bulk carrier. From the information on the differences between the predicted EHP and the actual instrumented delivery horsepower (DHP) of the existing 176K bulk carrier, the DHP of the

Table 10 Grid information and distribution

\begin{tabular}{lc}
\hline & Grid information \\
\hline Number of Grid points (half) & $3.6 \mathrm{M}$ \\
Number of grid block & 13 \\
Average $y+$ & $\sim 80$ \\
Half domain size $[x, y, z]$ & {$[-1.5 \mathrm{~L} \sim 2.5 \mathrm{~L}, 0 \mathrm{~L} \sim 1.0 \mathrm{~L},-1.0 \mathrm{~L} \sim 0.03 \mathrm{~L}]$} \\
\hline
\end{tabular}

Grid distribution

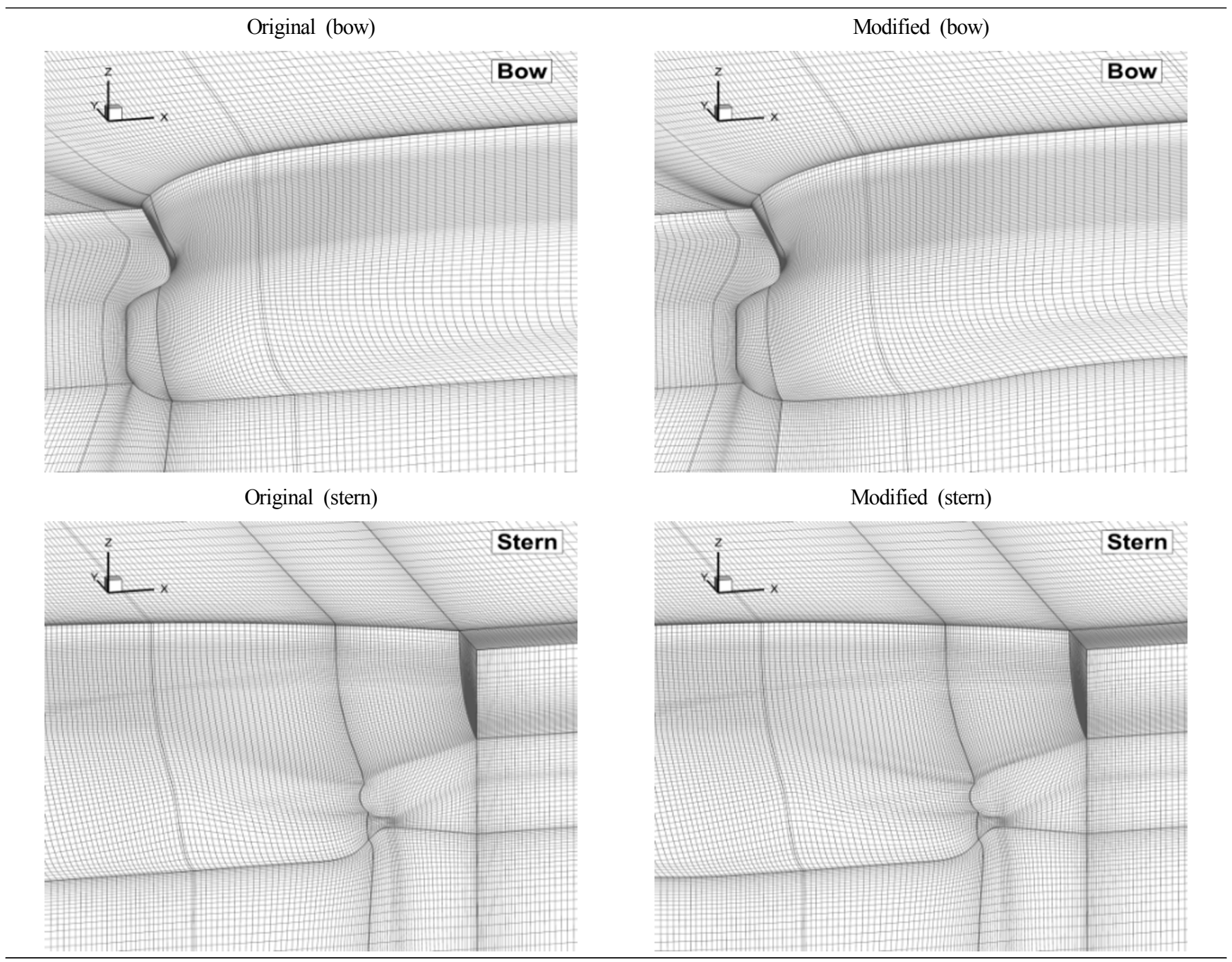


Table 11 Numerical resistance test results

\begin{tabular}{|c|c|c|c|c|c|c|c|c|c|c|c|c|c|}
\hline & \multicolumn{2}{|c|}{$V s$} & \multirow[b]{2}{*}{$F n$} & \multirow[b]{2}{*}{$R e$} & \multicolumn{3}{|c|}{ CFD (model scale) } & \multicolumn{2}{|c|}{ ITTC } & \multirow[b]{2}{*}{$\mathrm{Cr}$} & \multirow[b]{2}{*}{ Cts } & \multicolumn{2}{|c|}{ Full scale prediction } \\
\hline & $\mathrm{kt}$ & $\mathrm{m} / \mathrm{s}$ & & & $C f$ & $C p$ & $\mathrm{Ctm}$ & $C f m$ & $C f s$ & & & $\begin{array}{c}R \\
(\mathrm{kN})\end{array}$ & $\frac{E H P}{(\mathrm{~kW})}$ \\
\hline \multirow{4}{*}{ Original } & 12 & 6.173 & 0.1174 & $9.55 \mathrm{E}+06$ & 2.98151 & 0.60113 & 3.58264 & 3.02422 & 1.40958 & 0.55842 & 1.96800 & 768.7 & 4745.3 \\
\hline & 13 & 6.688 & 0.1272 & $1.03 \mathrm{E}+07$ & 2.94135 & 0.59370 & 3.53505 & 2.98244 & 1.39624 & 0.55261 & 1.94885 & 893.3 & 5974.5 \\
\hline & 14 & 7.202 & 0.1369 & $1.11 \mathrm{E}+07$ & 2.9053 & 0.59787 & 3.50317 & 2.94452 & 1.38406 & 0.55865 & 1.94271 & 1032.8 & 7438.5 \\
\hline & 15 & 7.717 & 0.1467 & $1.19 \mathrm{E}+07$ & 2.86288 & 0.61369 & 3.47657 & 2.90987 & 1.37286 & 0.56670 & 1.93956 & 1183.7 & 9134.1 \\
\hline \multirow{4}{*}{ Modified } & 12 & 6.173 & 0.1174 & $9.55 \mathrm{E}+06$ & 2.97653 & 0.73649 & 3.71303 & 3.02422 & 1.40958 & 0.68881 & 2.09839 & 784.4 & 4842.0 \\
\hline & 13 & 6.688 & 0.1272 & $1.03 \mathrm{E}+07$ & 2.92307 & 0.73461 & 3.65768 & 2.98244 & 1.39624 & 0.67524 & 2.07148 & 908.7 & 6077.3 \\
\hline & 14 & 7.202 & 0.1369 & $1.11 \mathrm{E}+07$ & 2.87961 & 0.74548 & 3.62509 & 2.94452 & 1.38406 & 0.68057 & 2.06463 & 1050.4 & 7565.3 \\
\hline & 15 & 7.717 & 0.1467 & $1.19 \mathrm{E}+07$ & 2.8348 & 0.75967 & 3.59447 & 2.90987 & 1.37286 & 0.68460 & 2.05746 & 1201.6 & 9272.6 \\
\hline
\end{tabular}

※ Vs: Velocity of the ship, CFD: Computational fluid dynamics, ITTC: The International Towing Tank Conference, Cf: friction resistance coefficient, $C p$ : prismatic coefficient, $C t m$ : total resistance coefficient of model-scale ship, $C f m$ : $C f$ of model-scale ship, $C f s$ : $C f$ of full-scale ship, $C r$ : residuary resistance coefficient, Cts: total resistance coefficient of full-scale ship, R: Resistance, EHP: Effective horse power

designed ship was estimated to have the same ratio for predicting fuel oil consumption as that of the designed ship at the actual scale.

For more detailed ship resistance performance comparison, model ship basin test has adopted. Fig. 5 shows model ships and Table 12 shows basin test results at same draft $(17.7 \mathrm{~m})$ conditions. From the test, EHP increased 5.25\% and BHP (Breake horse power) increased $6.55 \%$ on average from $12 \mathrm{kt}(6.173 \mathrm{~m} / \mathrm{s})$ to $15 \mathrm{kt}(7.717 \mathrm{~m} / \mathrm{s})$ compare to 'Original' hull form.

Empirically, losses in the cargo capacity can be compensated with an enlarged freeboard by considering the bulk general cargo loading condition. Assuming that the modified and original hull form has same cargo amount, the 'Original' hull form's draft can be reduced to 15.89 $\mathrm{m}$ when the draft of 'Modified' hull form fixed to $17.70 \mathrm{~m}$. At this time, the BHP gap between 'Modified' and 'Original' hull form

(a)

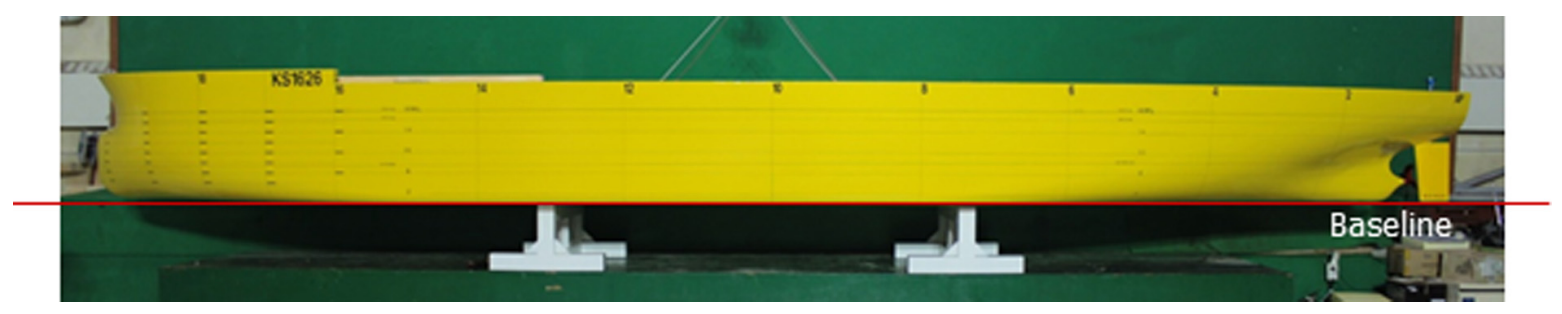

(b)

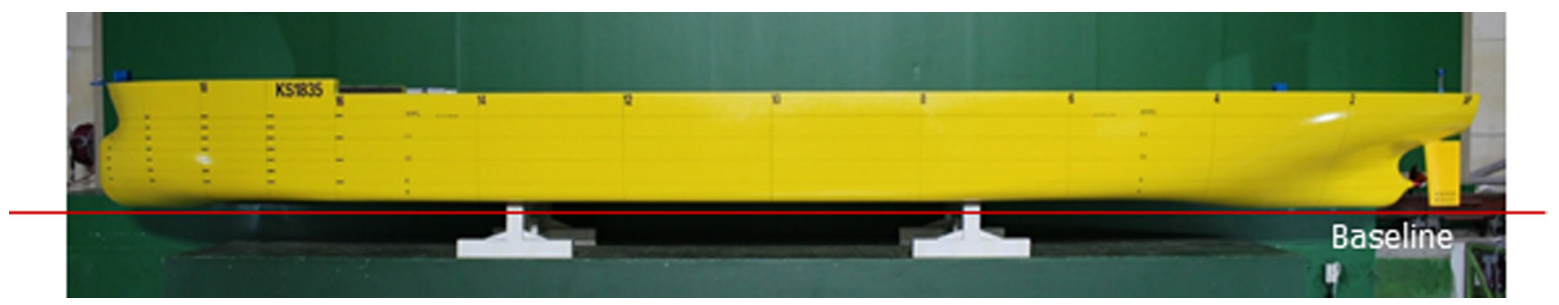

Fig. 5 Model ships, (a) original and (b) modified hull form

Table 12 Model ship basin resistance test results at same draft condition

\begin{tabular}{|c|c|c|c|c|c|c|c|c|}
\hline & \multicolumn{2}{|c|}{$V s$} & \multirow{2}{*}{$\begin{array}{c}P E \\
(\mathrm{~kW})\end{array}$} & \multirow{2}{*}{$\begin{array}{c}P B \\
(\mathrm{~kW})\end{array}$} & \multirow{2}{*}{$\begin{array}{l}R P M \\
(1 / \mathrm{s}) \\
\end{array}$} & \multirow{2}{*}{$\begin{array}{c}B H P \\
\text { increase }\end{array}$} & \multirow{2}{*}{$\begin{array}{c}R P M \\
\text { increase }\end{array}$} & \multirow{2}{*}{$\begin{array}{c}E H P \\
\text { increase }\end{array}$} \\
\hline & $\mathrm{kt}$ & $\mathrm{m} / \mathrm{s}$ & & & & & & \\
\hline \multirow{4}{*}{ Original } & 12 & 6.173 & 4391.0 & 6430.0 & 69.49 & - & - & - \\
\hline & 13 & 6.688 & 5528.0 & 8074.0 & 75.15 & - & - & - \\
\hline & 14 & 7.202 & 6871.0 & 10019.0 & 80.88 & - & - & - \\
\hline & 15 & 7.717 & 8538.0 & 12462.0 & 86.97 & - & - & - \\
\hline \multirow{4}{*}{ Modified } & 12 & 6.173 & 4601.8 & 6832.0 & 70.62 & $6.3 \%$ & $1.6 \%$ & $4.8 \%$ \\
\hline & 13 & 6.688 & 5819.8 & 8609.0 & 76.43 & $6.6 \%$ & $1.7 \%$ & $5.3 \%$ \\
\hline & 14 & 7.202 & 7261.8 & 10716.0 & 82.32 & $7.0 \%$ & $1.8 \%$ & $5.7 \%$ \\
\hline & 15 & 7.717 & 8981.0 & 13248.0 & 88.36 & $6.3 \%$ & $1.6 \%$ & $5.2 \%$ \\
\hline
\end{tabular}




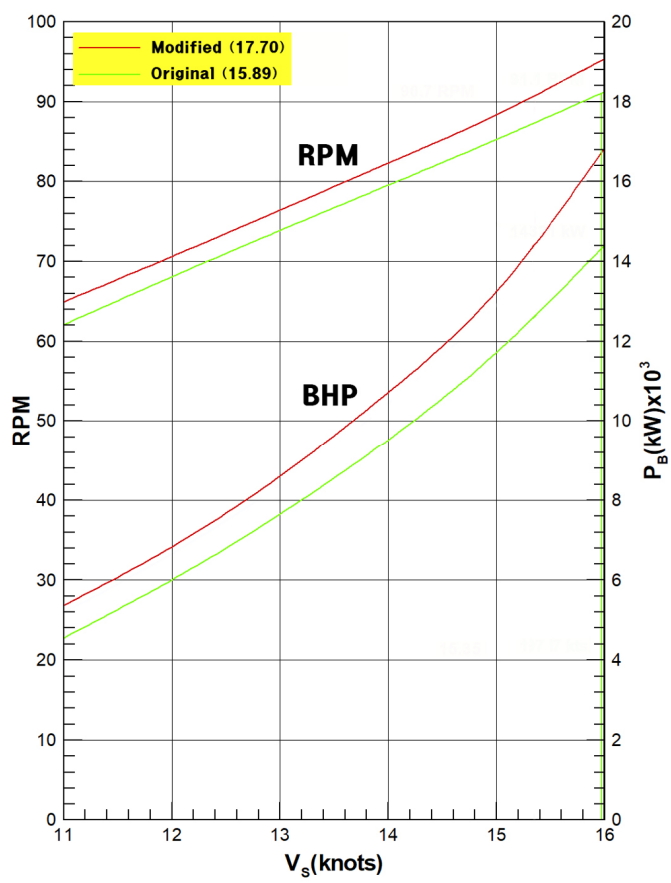

Fig. 6 BHP and RPM, (a) original and (b) modified hull form

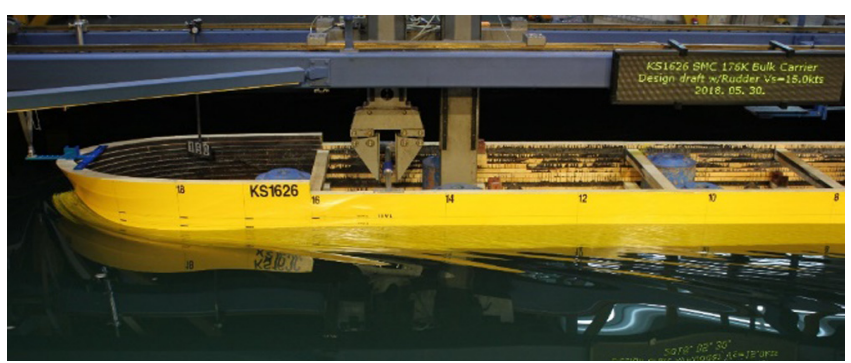

(a)

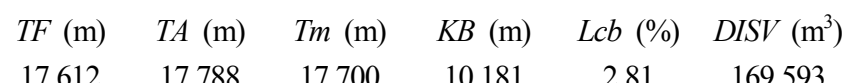

increases more than $12.5 \%$ as shown in Fig. 6. Fig. 7 shows model ship basin test pictures, conditions and nominal velocity contour at propeller plane at same displacement condition and Fig. 6 shows RPM and BHP of 'Modified' and 'Original' hull forms.

To compensate loses in ship resistance performance of 'modified' hull form, flow stress intensive parts of hull geometry as shown in Fig. 8 shall be improved. Moreover, enlarged beam width can be considered to increase cargo loading capacity of 'modified' hull form.

Regarding the sea keeping ability, the characteristics of the ship motion in sea waves are important. As shown in Fig. 9, compared to the original hull form, although the modified hull form shows lack of sea keeping performance in heave and roll motion, the pitch motion characteristics of the 'modified' hull form do not significantly differ from those of the original hull form. To analyze ship behavior characteristics, SMTP (Ship motion total package), which is the KRISO's in-house simulation tool (new version of SURVSHIP (Survivability of ship)) has used (Lee, 2015). In the simulation, 0.02 second time step has applied. Figure 6 shows ship behavior characteristics in the regular wave with beam-sea (entrance angle of 90 degree) condition. Due to uneven baseline, suggested hull form shows

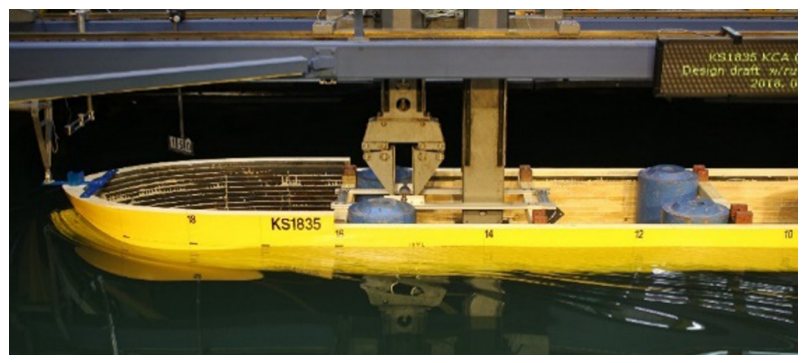

(b)

$\begin{array}{cccccc}T F(\mathrm{~m}) & T A(\mathrm{~m}) & T m(\mathrm{~m}) & K B(\mathrm{~m}) & \operatorname{Lcb}(\%) & \operatorname{DISV}\left(\mathrm{m}^{3}\right) \\ 15.890 & 15.890 & 15.890 & 8.244 & 3.56 & 169,593\end{array}$
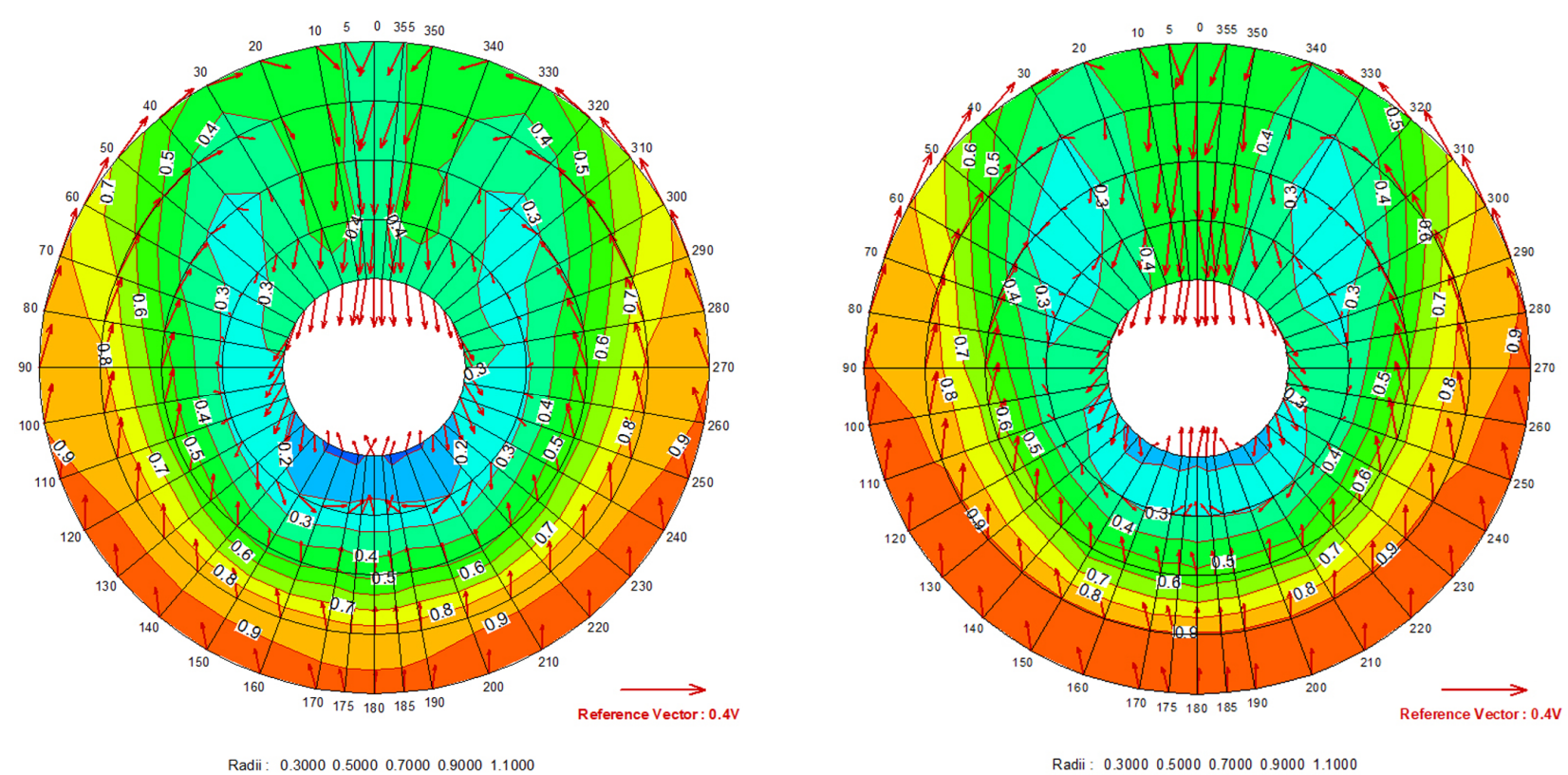

Fig. 7 Model ship basin tests (above) and nominal velocity contour at propeller plane (below), (a) original and (b) modified hull form at same displacement condition 


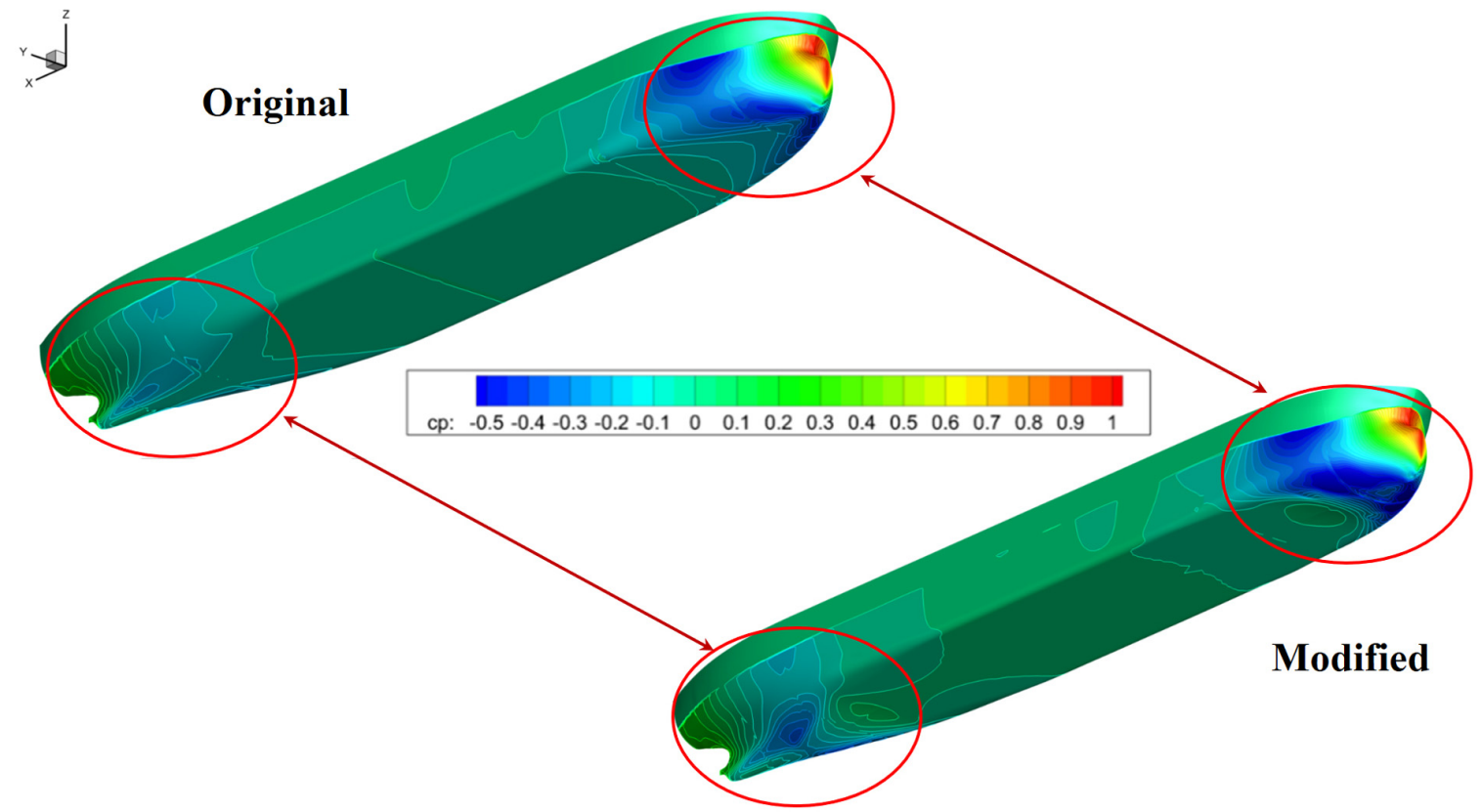

Fig. 8 Comparison of the pressure distribution between the original (above) and the modified (below) hull form
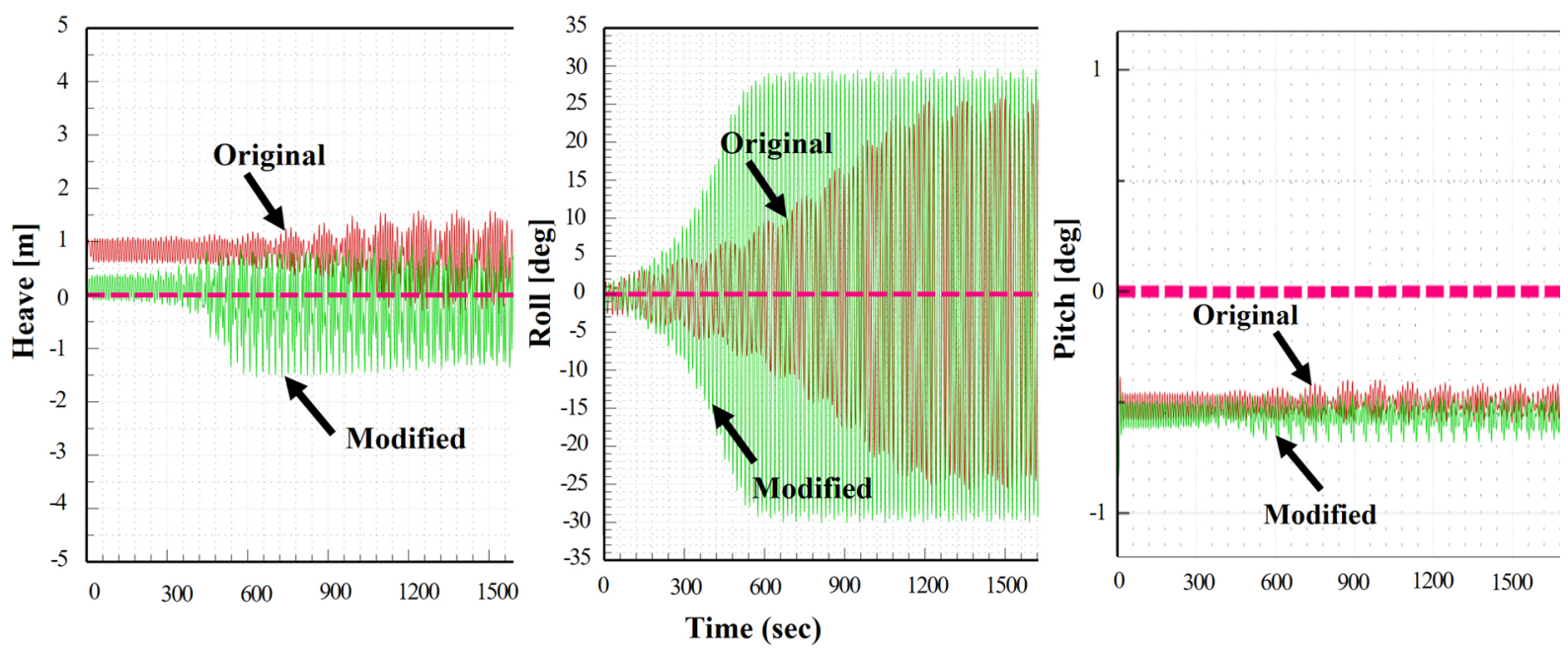

Fig. 9 Sample of the designed ship's motion analysis results in waves under fully loaded conditions (wave height: $2 \mathrm{~m}$, beam sea condition)

lack of seakeeping ability especially in heave and roll motions. In case of Heave motion, it is estimated that waves between bow and stern uneven baseline enlarges ship motion compare to 'original' hull form. For roll motion, it is estimated that shorten immersion depth of 'modified' hull form enlarges initial roll motion.

To compensate for the losses in the ship motion under waves, relationship between the geometry of mid-ship section and roll damping will be considered (Park et al., 2019). If the propeller diameter is decreased to accommodate for the adjusted ship speed and the engine performance, then the elevating height of the baseline of the cargo holds can be decreased to secure the proper cargo capacity, ship resistance, and seakeeping performance. When considering only the mid-ship section of the suggested uneven baseline minimal ballast bulk carrier, a decrease in the depth of the cargo holds will lead to a decrease in the ultimate bending moment capacity. To compensate for the decreased ultimate bending moment capacity, the weight of the ship's structure can be increased. For this reason, in order to convince the technical feasibility of the suggested uneven baseline minimal ballast bulk carrier, the structural design evaluation under different sea states should be adopted in the next study.

\section{Conclusion}

To design a new minimal ballast ship which operate certain amount of permanent ballast for ballast-water free operation, the existing alternatives for ballast water were reviewed. To overcome the lack of berth access and loading constraints of the MIBS / NOBS 'storm ballast', the conceptually an uneven baseline basis 'no or minimal 
discharge' alternative so called 'modified' hull form suggested. To generate the 'modified' concept, a simplified systems engineeringbased design approach was adopted. By examining the roles of the ballast water and existing alternatives, seven general requirements for a new minimal ballast ship and one specific requirement for overcoming the penalties of a 'storm ballast' were identified. Then, five functional requirements were generated for the uneven baseline minimal ballast vessel. As suggested, the concept has wide and parallel sides compared to the existing V-hull design of a 'storm ballast', so the lack of berth access capability can be compensated theoretically. As for loading constraints, the smaller beam size of the suggested concept compare to exiting MIBS / NOBS concept can be helpful in compensating for the load constraints. However, during the model ship basin test, under the same draft conditions, the EHP of 'modified' increased $5.25 \%$ and BHP increased $6.55 \%$ on average compare to 'original' hull form. Given the loss in cargo loading capacity, the suggested 'modified' hull form's economic feasibility is assessed at an awkward level. So, resistance performance at same displacement condition has also tested via model ship basin test. From the basin test, more than 12.5 loss in BHP has convinced. From this review result, losses in the cargo capacity and ship resistance performance shall be consider concurrently in the design phase to have technical and economic feasibility. By optimizing the geometry and dimension of the 'modified' hull form, a certain amount of loss in resistance performance and cargo capacity shall be compensated in the next study. Although the suggested uneven baseline basis 'modified' hull form has many rooms for commercializing, the suggested design, evaluation process and methodologies can be adapted to generate various attempts at developing non/minimal ballast ships to keep the healthy ocean environment from organisms of different ecosystems or a large amount of sterile sea water.

\section{Acknowledgements}

The initial concept of an 'uneven baseline minimal ballast water bulk carrier' was introduced as a proceeding at the 17th International Congress on Maritime Transportation and Harvesting of Sea Resources (IMAM) (Kang et al., 2017) and concretized in this study. This research was supported by a grant from the National R\&D Project of KRISO research project PES3000.

\section{References}

Albert, R.J., Lishman, J.M., \& Saxena, J.R. (2013). Ballast Water Regulations and the Move Toward Concentration Based Numeric Discharge Limits. Ecological Applications. 23(2), 289-300. https://doi.org/10.1890/12-0669.1

GEF, U., \& IMO, G.P. (2011). GESAMP. Establishing Equivalency in the Performance Testing and Compliance Monitoring of Emerging Alternative Ballast Water Management Systems
(EABWMS), A Technical Review.

Isbester, J. (2010). Bulk Carrier Practice. Nautical Institute.

Kang, H.J., Yang, Y.-S., Ki, M.S., Shin, M.S., Choi, J., Cha, J.H., \& Lee, D. (2016). A Concept Study for Cost Effective NGH Mid-stream Supply Chain Establishing Strategies. Ocean Engineering, 113, 162-173. https://doi.org/10.1016/j.oceaneng. 2015.12.052

Kang, H.J., Choi, J., Ahn, H.-S., \& Kim, K.-S. (2017). Systems Engineering-basis Feasibility Study for Development of Ballast Water-Free Vessel. Proceedings of IMAM 2017, Maritime Transportation and Harvesting of Sea Resources. Lisbon, Portugal.

Kerr, S. (1994). Ballast Water Ports and Shipping Study (No. 5). AGPS.

Kim, J., Park, I.R., Kim, K.S., Van, S.H., \& Kim, Y.C. (2011) Development of Numerical Method for the Evaluation of Ship Resistance and Self-Propulsion Performances. Journal of the Society of Naval Architects of Korea. 48(2), 147-157. https://doi.org/10.3744/SNAK.2011.48.2.147

Kim, Y.C., Kim, K.S., \& Kim, J. (2014). Numerical Prediction of Ship Hydrodynamic Performances using Explicit Algebraic Reynolds Stress Turbulence Model. Journal of the Society of Naval Architects of Korea. 51(1), 67-77. https://doi.org/ 10.3744/SNAK.2014.51.1.67

Lee, G.J. (2015). Dynamic Orifice Flow Model and Compartment Models for Flooding Simulation of a Damaged Ship. Ocean Engineering Journal, 109, 635-653. https://doi.org/10.1016/ j.oceaneng.2015.09.051

Leonard, J. (1999). Systems Engineering Fundamentals. Defense Ssystems Management Coll Fort Belvoir VA.

Parsons, M.G., \& Kotinis, M. (2011a). Refinement of the BallastFree Ship Concept, Department of Naval Architecture and Marine Engineering. University of Michigan.

Parsons, M.G., \& Kotinis, M. (2011b). Trim and Draft Control Capability of the Variable Buoyancy Ship. Journal of Ship Production and Design. 27(3), 118-126.

Park, B., Jung, D.W., Jung, J., Park, I., Cho, S.K., \& Sung, H.G. (2019). Experimental Study on Estimation of Roll Damping for Various Mid-ship Sections. Journal of Ocean Engineering Technology. 33(4), 322-329. https://doi.org/10.26748/KSOE. 2019.004

Shingo, S. (2014). Preliminary Hull Form Planning for Non-Ballast Water Ship and Minimal Ballast Water Ship (1 ${ }^{\text {st }}$ Report)Simplified Estimation Method of Propulsive Performance. Journal of the Japan Society of Naval Architects and Ocean Engineers. 20, 21-26. https://doi.org/10.2534/jjasnaoe.20.21

Werschkun, B., Banerji, S., Basurko, O.C., David, M., Fuhr, F., Gollasch, S., ... Kehrer, A. (2014). Emerging Risks from Ballast Water Treatment: The Run-up to the International Ballast Water Management Convention. Chemosphere. 112, 256-266. https://doi.org/10.1016/j.chemosphere.2014.03.135 


\section{Author ORCIDs and Contributions}

$\begin{array}{lll}\text { Author name } & \text { ORCID } & \text { Contributions } \\ \text { Kang, Hee Jin } & 0000-0002-8241-3751 & \text { (1)(4)(5) } \\ \text { Kim, Kwang-Soo } & 0000-0001-7548-7157 & (3) \\ \text { Choi, Jin } & 0000-0001-9842-2049 & (3) \\ \text { Lee, Yeong-Yeon } & 0000-0002-0408-6222 & (2) \\ \text { Ahn, Haeseong } & 0000-0001-6330-3744 & (5) \\ \text { Yim, Geun-Tae } & 0000-0002-5382-8931 & (2) \\ \text { (1) Conceived of the presented idea or developed the theory } \\ \text { (2) Carried out the experiment or collected the data } \\ \text { (3) Performed the analytic calculations or numerical simulations } \\ \text { (4) Wrote the manuscript } \\ \text { (5) Supervised the findings of this study }\end{array}$

